\title{
Pricing scheme of cruise based on the forecast
}

\author{
An Qi Wang ${ }^{1, a}$ \\ ${ }^{1}$ North China Electric Power University (Bao Ding), Hebei, China \\ a2680416176@qq.com
}

Keywords: Optimal Pricing Scheme Multiplicative Pickup Exponential Smoothing Maximum Revenue

\begin{abstract}
As the number of cruise passengers increases, the cruise companies develop rapidly in recent years. To create maximum revenue for the companies, it's become more important that how to make a reasonable price decision and absorb as many passengers as possible. In this paper, there are two models built to determine the optimal pricing scheme. The first is a model of multiplicative pickup, which is used to forecast predetermined number of cruise passengers in weekly voyage. The second is an exponential smoothing model, which is to help us forecast the predetermined price of various cabins in weekly voyage. Finally, according to the predetermined price and corresponding predetermined number of cruise passengers we can determine the expected maximum revenue.
\end{abstract}

\section{Introduction}

Cruise ship which is originated from Europe originally means transporting mail by ship, so it's mainly used in transportation rather than tourism. Recently, with the development of aeronautic technology, the cruise ship used in transportation largely disappears and modern cruise ship with a comprehensive tourism character has already gathered transportation, amusement, accommodation, catering and shopping in an integral whole.

Furthermore, cruise industry as a kind of modern tourism is one of the fastest growing industries with a growing rate above $10 \%$ in recent years. After building the "quantum of the seas" of Royal Caribbean International, cruise industry entered a completely new era of development in its history [1].

\section{Analysis of Pricing and Revenue}

Nowadays cruise companies mostly adopt the way of pre-ordering to sell tickets. To be effective, tourists should pre-order tickects from 14 to 0 weeks prior to departure of cruise ship. In order to forecast the revenue in weekly voyage, accordingly these companies refer to previous data containing predetermined number of cruise passengers and predetermined price from 14 to 0 weeks prior to departure[2]. There are various kinds of cabins in present cruise ships, generally divided into the first, second and third class cabin. Through making a reasonable price decision for various kinds of cabins, the companies can absorb as many passengers as possible and create maximum revenue.

In this paper, we use data of some cruise ship with 1200 cabins about predetermined number of cruise passengers and predetermined price of various cabins in recent weekly voyage to study the price decision. There are 250 first class cabins, 450 second class cabins and 500 third class cabins in this cruise ship.We establish the forecast models by part of predetermined number of cruise passengers, total predetermined number of cruise passengers and predetermined price of various cabins in 10 times voyage.

\section{Predetermined Number Prediction of Various Cabins}

\subsection{Multiplicative Pickup model}


Multiplicative Pickup is a method of forecasting future requirment based on the increasing percentage, which means increasing requirment in a finite time as a percent of previous total requirment, namely:

$$
R_{c}^{k}(\mathrm{i})=\frac{X_{c-1}^{k}(i)-X_{c}^{k}(i)}{X_{c}^{k}(i)} \times 100 \%
$$

Where: $R_{c}^{k}(\mathrm{i})$ is the increasing percentage of NO. $\mathrm{k}$ class cabins of the $\mathrm{i}$ times voyage c weeks prior to departure. $X_{c-1}^{k}(i)$ is the previous total requirment of NO. $\mathrm{k}$ class cabins of the $\mathrm{i}$ times voyage c-1weeks prior to departure. When there are the first, second and third class cabin., $\mathrm{k}=1,2,3$.

Where we can forecast the previous total requirment of NO. $k$ class cabins of the $n+1$ times voyage c-1weeks prior to departure by following formula.

$$
X_{c-1}^{k}(n+1)=\frac{\sum_{i=1}^{n} R_{c}^{k}(i)}{n} \times X_{c}^{k}(n+1)+X_{c}^{k}(n+1)
$$

Where: $X_{c-1}^{k}(n+1)$ is the previous total requirment of NO. $\mathrm{k}$ class cabins of the $\mathrm{n}+1$ times voyage c-1weeks prior to departure. $X_{c}^{k}(n+1)$ is the previous total requirment of NO. $\mathrm{k}$ class cabins of the $\mathrm{n}+1$ times voyage c weeks prior to departure.

\subsection{Solution method and calculation for model}

To forecast the previous total requirment of NO. $k$ class cabins of the $n+1$ times voyage in the week of number c-1, namely $X_{c-1}^{k}(n+1)$, we list the predetermined number in weekly voyage of some cruise ship with 250 first class cabins $(k=1)$ as shown in Table 1. Through the known data we can forecast the data of $X_{c-1}^{k}(n+1)$ as shown in yellow, the forecasts of other kinds of cabins are the same with it[3].

Table 1. Actual and forecast predetermined number of first class cabin

\begin{tabular}{ccccccccccc}
\hline Weeks before departure & 1 & 2 & 3 & 4 & 5 & 6 & 7 & 8 & 9 & 10 \\
\hline 14 & 0 & 1 & 0 & 0 & 2 & 1 & 2 & 0 & 0 & 1 \\
13 & 1 & 2 & 3 & 0 & 5 & 3 & 4 & 0 & 0 & 4 \\
12 & 3 & 4 & 6 & 3 & 10 & 6 & 7 & 4 & 1 & 8 \\
11 & 9 & 8 & 10 & 5 & 15 & 11 & 9 & 6 & 5 & 11 \\
10 & 12 & 13 & 16 & 9 & 21 & 16 & 15 & 10 & 9 & 13 \\
9 & 17 & 20 & 23 & 18 & 31 & 24 & 21 & 22 & 20 & 23 \\
8 & 31 & 39 & 37 & 33 & 48 & 32 & 33 & 39 & 38 & 36 \\
7 & 54 & 61 & 59 & 53 & 62 & 55 & 51 & 61 & 63 & 52 \\
6 & 83 & 85 & 88 & 81 & 79 & 76 & 83 & 82 & 81 & 83 \\
5 & 10 & 102 & 111 & 103 & 108 & 99 & 102 & 106 & 109 & 106 \\
4 & 13 & 136 & 136 & 141 & 134 & 131 & 142 & 133 & 141 & 138 \\
3 & 16 & 170 & 173 & 184 & 171 & 168 & 193 & 170 & 181 & 177 \\
2 & 16 & 178 & 201 & 205 & 193 & 190 & 213 & 188 & 200 & 196 \\
1 & 17 & 184 & 210 & 210 & 200 & 196 & 220 & 194 & 206 & 201 \\
0 & 17 & 184 & 213 & 212 & 201 & 197 & 221 & 195 & 208 & 203 \\
\hline
\end{tabular}

We take predetermined number of the fifth voyage in 0 week prior to departure for example. First, use actual predetermined number in 1 and 0 week prior to departure of first four times voyages to calculate increasing percentage respectively. Then, calculate the mean of all increasing percentages. Finally,get the predetermined number of the fifth voyage in 0 week prior to departure[4]. The concrete process is as follows

$$
X_{0}^{1}(5)=\left[\left(\frac{171-170}{170}+\frac{184-184}{184}+\frac{213-210}{210}+\frac{212-210}{210}\right) / 4\right] \times 200+200=201
$$

To present the results clearly, we choose predetermined number of the second and sixth voyages in every week prior to departure to curve plotting. From Figure1,we can draw a conclusion that the predermined number in weekly voyage generally appears a apparent"S"curve and the growth rate firstly increases to largest about in 10 weeks prior to departure and then decreases to 0. 


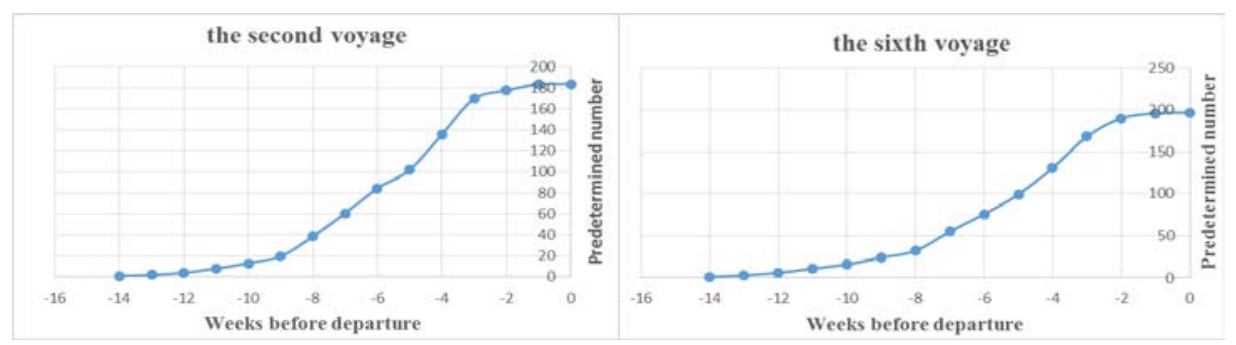

Figure1. Predetermined number of the second and sixth voyages

\section{Predetermined Price Prediction of Various Cabins}

\subsection{Exponential smoothing model}

Exponential smoothing is one of the most popular forecast methods of revenue management.With a stable and simple feature, it's generally utilized to get better prediction accuracy by less information. The essence of this method is smoothing predicted data according to time-sequence and get the change rule and trend to make a prediction. According to smoothing frequency, the method is subdivided into single exponential smoothing, double exponential smoothing and higher order exponential smoothing[5]. Considering that the higher order exponential smoothing is seldom used, we mainly introduce single exponential smoothing in this paper.

$$
F_{c}^{k}(i+1)=\alpha T_{c}^{k}(i)+(1-\alpha) F_{c}^{k}(i)
$$

Where: $F_{c}^{k}(i+1)$ is predicted value of the $i+1$ times voyage, namely smoothing value of the $\mathrm{i}+1$ times voyage. $T_{c}^{k}(i)$ is actual value of the i times voyage. $F_{c}^{k}(i)$ is predicted value of the $\mathrm{i}$ times voyage. $\alpha$ is smooth coefficient, also known as weighting factor, and $0<\alpha<1$. According to experience judgment when $\alpha=0.6$, our model have a high sensitivity.

If there are some determined data before actual value, the mean of them is used to be the initial value.

\subsection{Solution method and calculation for model}

To forecast the predetermined price of various cabins in weekly voyage, we list the predetermined price in weekly voyage of some cruise ship with 250 first class cabins $(\mathrm{k}=1)$ as shown in Table 2. Through the known data we can forecast the data of $F_{c}^{k}(i+1)$ as shown in yellow, the forecasts of other kinds of cabins are the same with it.

Table 2. Actual and forecast predetermined price of first class cabin

\begin{tabular}{ccccccccccc}
\hline Weeks before departure & 1 & 2 & 3 & 4 & 5 & 6 & 7 & 8 & 9 & 10 \\
\hline 14 & 151 & 1580 & 1610 & 1550 & 1530 & 1600 & 1520 & 1530 & 1590 & 1520 \\
13 & 153 & 1580 & 1650 & 1620 & 1570 & 1610 & 1590 & 1610 & 1650 & 1590 \\
12 & 172 & 1700 & 1730 & 1640 & 1690 & 1720 & 1690 & 1690 & 1740 & 1660 \\
11 & 175 & 1740 & 1730 & 1690 & 1760 & 1800 & 1730 & 1680 & 1790 & 1660 \\
10 & 175 & 1860 & 1770 & 1840 & 1880 & 1840 & 1860 & 1780 & 1860 & 1770 \\
9 & 177 & 1860 & 1780 & 1890 & 1900 & 1850 & 1860 & 1850 & 1860 & 1790 \\
8 & 190 & 1950 & 1830 & 1960 & 1970 & 1940 & 1930 & 1970 & 1900 & 1870 \\
7 & 192 & 1960 & 1830 & 1960 & 1990 & 1930 & 1950 & 1970 & 1920 & 1870 \\
6 & 194 & 1950 & 1830 & 1850 & 1960 & 1900 & 1840 & 1930 & 1830 & 1840 \\
5 & 196 & 1950 & 1950 & 1910 & 1970 & 1900 & 1810 & 1840 & 1820 & 1849 \\
4 & 195 & 1930 & 1930 & 1870 & 1880 & 1820 & 1810 & 1870 & 1792 & 1821 \\
3 & 177 & 1990 & 1800 & 1860 & 1900 & 1860 & 1760 & 1820 & 1744 & 1772 \\
2 & 173 & 1820 & 1720 & 1760 & 1810 & 1710 & 1674 & 1733 & 1659 & 1686 \\
1 & 166 & 1720 & 1800 & 1810 & 1720 & 1685 & 1650 & 1708 & 1634 & 1661 \\
0 & 161 & 1650 & 1790 & 1690 & 1658 & 1624 & 1589 & 1647 & 1573 & 1601 \\
\hline
\end{tabular}

We take predetermined price of the fifth voyage in 0 week prior to departure for the first example. Use actual predetermined price in 0 week prior to departure of first three times voyages to calculate the fourth actual predetermined price $T_{0}^{1}(4)$. Utilize smooth coefficient and expectant predetermined price in 0 week prior to departure of the fourth voyage $F_{0}^{1}(4)$ to calculate forecast of the fifth voyage, namely $F_{0}^{1}(5)$. The concrete process is as follows:

$$
T_{0}^{1}(4)=\frac{1610+1650+1790}{3} ; \quad F_{0}^{1}(5)=0.6 \times T_{0}^{1}(4)+(1-0.6) \times F_{0}^{1}(4)=1658
$$


According to actual and forecast predetermined price in 0 week prior to departure of the fifth voyage,we can get the forecast predetermined price of the sixth voyage by following formula. Through the definition of exponential smoothing, in the formula, $T_{0}^{1}(5)=F_{0}^{1}(4)$.

$$
F_{0}^{1}(6)=0.6 \times T_{0}^{1}(5)+(1-0.6) \times F_{0}^{1}(5)
$$

\section{Maximum revenue based on cumulative optimal values}

To create maximum revenue, the total revenue model is divided into several part modules which all need to achieve optimization. Indeed, the solution of maximum revenue is influenced by many constraints so that it is by no means a simple accumulation of the optimal values[6]. In this context, we use as many optimal values which meet conditions as possible to accumulate.

According to different weeks prior to departure of the cruise ship, we divide the total revenue model into 15 modules from which we need to calculate the every voyage revenue and select the maximum revenue. Finaly, accumulate every maximum revenue as well as consider the conditions to get total maximum revenue.

Through the analysis about predetermined number and price of above sections, we give the calculating method of every voyage revenue as follows:

$$
Y_{c}=\max \left\{\Delta X_{c}^{k}(i) \cdot F_{c}^{k}(i)\right\} \begin{cases}\Delta X_{c}^{k}(i)=X_{c}^{k}(i)-X_{c+1}^{k}(i) & c=0,1 \ldots 13 \\ \Delta X_{c}^{k}(i)=X_{c}^{k}(i) & c=14 \\ i=1,2 \ldots 10 \quad k=1,2,3 & \end{cases}
$$

The total maximum revenue is shown as follows:

$$
Z_{k}=\sum_{c=0}^{14} Y_{c}
$$

Where: $Y_{c}$ is voyage revenue in c weeks prior to departure, $\Delta X_{c}^{k}(i)$ is incremental predetermined number of every week, $F_{c}^{k}(i)$ is predetermined price in c weeks prior to departure of the i times voyage, $Z_{k}$ is the total maximum revenue by accumulation of the optimal voyage revenue.

In this paper, we list data of some cruise ship with 1200 cabins about predetermined number of cruise passengers to study the price decision. And there are 250 first class cabins, 450 second class cabins and 500 third class cabins in this cruise ship. For this reason, the constraint of this model is that the predetermined number of cruise passengers are no more than corresponding cabins.

\section{Summary}

In this paper, we study the expected maximum revenue of cruise ship based on multiplicative pickup and exponential smoothing models. Through establishing two forecast models of predetermined number and price in weekly voyage of various cabins, we get the pricing scheme by which the method of cumulative optimal values to get expected maximum revenue of cruise ship is proposed. Furthermore, according to a limited number of cabins and bounded price range, the final maximum revenue can be determined.

\section{References}

[1] Seidl A, Guillano F, Pratt L. Cruise tourism and community economic development in Central America and the Caribbean: The case of Costa Rica[J]. Pasos, 2006, 4(2): 213-224. Reference to a book:

[2] Sun X, Gauri D K, Webster S. Forecasting for cruise line revenue management[J]. Journal of Revenue and Pricing management, 2011, 10(4): 306-324.

[3] Shoukui Si, Xijing Sun. Mathematical modeling algorithm and application[M]. National defence industry press, 2011. 
[4] Jiang Qiyuan, the mathematical model (the Second Edition ), higher education press, 1991

[5] Billah B, King M L, Snyder R D, et al. Exponential smoothing model selection for forecasting[J]. International journal of forecasting, 2006, 22(2): 239-247.

[6] Bobb L M, Veral E. Open issues and future directions in revenue management[J]. Journal of Revenue and Pricing Management, 2008, 7(3): 291-301. 